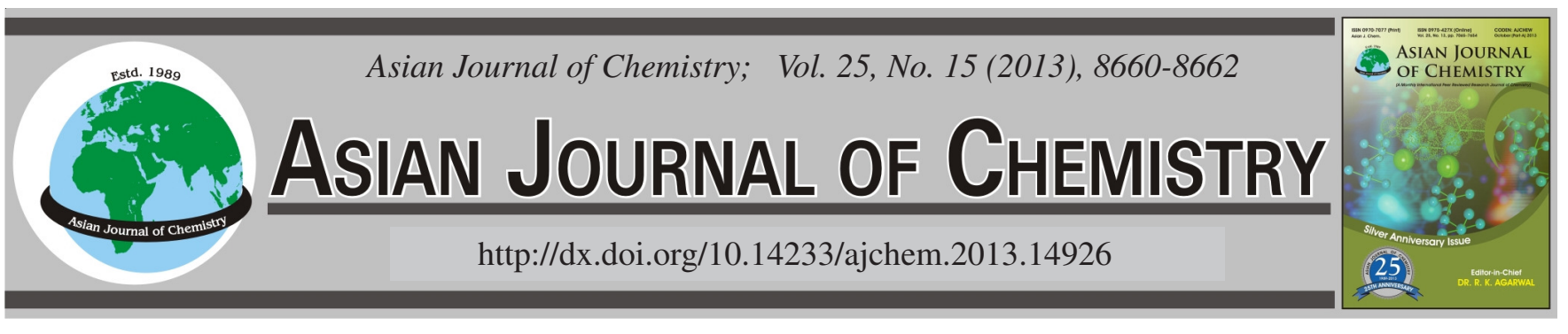

\title{
Low-Temperature Oxidation Properties of Carboxyl in Coal Based on Model Compound of Spontaneous Combustion of Coal
}

\author{
Yibo TAng ${ }^{*}$, Zenghua Li, DonguUan Ma and Huaijun Ji
}

School of Safety Engineering, China University of Mining and Technology, Xuzhou 221008, P.R. China

*Corresponding author: E-mail: tangyibo11@126.com

\begin{abstract}
According to coal spontaneous combustion theory and coal molecular structure, benzoic acid was adopted as model compound of coal | spontaneous combustion by temperature programming to study oxidation reaction under different temperatures (293-423 K). Besides, the generated oxidation products under different reaction conditions were analyzed qualitatively and quantitatively via GC-MS. Reaction temperature and reaction time are the major factors which affect low-temperature oxidation of benzoic acid. This study has provided reference for low-temperature oxidation properties of sole activity structure in coal molecular structure from chemical perspective.

Key Words: Low-temperature oxidation, Carboxyl, Benzoic acid, Model compound, Coal spontaneous combustion.
\end{abstract}

\section{INTRODUCTION}

Spontaneous combustion of coal is a main disaster in coal industry, which universal occurs in underground coal mining ${ }^{1}$. For centuries, people try to study the mechanism of spontaneous combustion of $\mathrm{coal}^{2-4}$. The traditional method for elaborating spontaneous combustion of coal always focus on the change of thermodynamic parameters and mathematical model in low-temperature oxidation of $\mathrm{coal}^{5,6}$. At present, with the development of analytical chemistry, researchers increasing pay attention to study spontaneous combustion of coal by chemical view $^{7-10}$. Those research mentalities rely on detection of variation with coal molecular structure before and after the low-temperature to reveal the mechanism of spontaneous combustion of coal comprehensively. Infrared spectroscopy was employed as a measure for providing reference on the transform of functional groups in coal after self-heating of $\mathrm{coal}^{11,12}$. But it is difficult to assure the accuracy of these results due to the fact that the coal molecular structure is extremely complex and erratic.

For simplifying the complex molecular structure of coal, we selected mode compounds to research some special structure in coal on the low-temperature oxidation ${ }^{13}$. The main structural units of the coal are condensation aromatic and heterocyclic aromatic and these structural units are connected by several active groups and bridge bonds ${ }^{14}$. Chemical properties of condensation aromatic and heterocyclic aromatic compound are relatively stable. Therefore, the active side-chains are considered to be the main target for studying spontaneous combustion of coal ${ }^{15}$. As a common functional group in coal, the carboxyl mainly exists in the peat, lignite and weathered coal, but the carboxyl group disappears while the carbon content of coal is greater than $78 \%{ }^{16}$. As a result, the aromatic compound which includes single active group (carboxyl) was selected as the model compound.

\section{EXPERIMENTAL}

The detailed parameters of selected model compounds can be seen is Table-1.

\begin{tabular}{cc} 
TABLE-1 \\
MODEL COMPOUND FOR SPONTANEOUS \\
COMBUSTION OF COAL \\
\hline Model compound & Coal functional group \\
\hline & \\
Benzoic acid & $-\mathrm{COOH}$ \\
\hline
\end{tabular}

The schematic diagram of experimental apparatus was shown in Fig. 1. In experimental system, $0.02 \mathrm{~L} / \mathrm{min}$ dry air uniformly passes through the pipeline. The temperature control system assures that the sample can enable to be conducted by temperature programming and stabilized at setting temperature. The experiment was divided into two parts. The sample can is a cylindrical container made of brass which has a diameter of $48 \mathrm{~mm}$ and a height of $105 \mathrm{~mm}$. The bottom and 


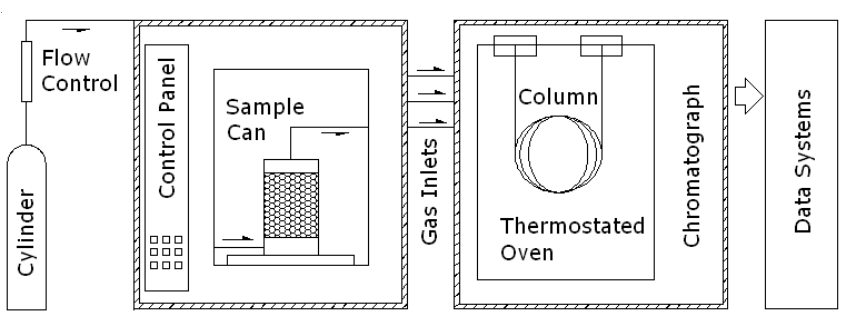

Fig. 1. Experimental set-up

top sample can are equipped with gas inlet and gas outlet, respectively. The pore in the central sample can be installed by temperature sensor contact whose top is exactly located in the geometric center.

Procedure: In order to simulate coal particles and create "gas-solid reaction" condition similar with self-heating oxidation of coal from the physical perspective, using a kind of solid particle to simulate particle state of coal under normal state was proposed in this paper. Besides, this kind of solid particle is out of circulation with experimental reaction which can avoid disturbing the study of oxidation reaction characteristics of model compound. Through comparing and contrasting, algae soil supporters with the particle size of 0.180 $0.250 \mathrm{~mm}$ were employed to simulate the particle state of coal. First, take $2.5 \mathrm{~g}$ benzoic acid and $10 \mathrm{~g}$ acetone with electronic balance and then uniformly mix them. Next, pour into $40 \mathrm{~g}$ supporter and stir it with glass rod so as to make acetone and model compound evenly attached to supporter surface. Then, pour supporter with attached model compound into an enamel tray and evenly lay it flat on the tray. The vacuum drying is subjected for $24 \mathrm{~h}$ to make acetone volatilize. After acetone fully volatilizes, model compound would be attached to the supporter evenly. After that, place it into the sample can and make the experiment. Besides, heating furnace needs to be set to conduct temperature programming from 293 to $423 \mathrm{~K}$. At each setting temperature, gaseous products of reaction need to be collected. In addition, concentration variation of reaction products would be analyzed qualitatively and quantitatively by making use of gas chromatograph.

\section{RESULTS AND DISCUSSION}

Effects of temperature: By testing gaseous products of model compound generated by oxidation under different temperatures, it can be found that concentration of $\mathrm{CO}$ and $\mathrm{CO}_{2}$ after reaction was shown in Fig. 2. In the process of oxidation, oxidative activity of benzoic acid was always weak until the temperature reached to $353 \mathrm{~K}$. Also, the concentration of $\mathrm{CO}$ remained at zero level. Once the temperature reached to $353 \mathrm{~K}$, the $\mathrm{CO}$ was generated in reaction $(7.36 \mathrm{ppm})$. The production of $\mathrm{CO}$ started to increase substantially. From 353 to $423 \mathrm{~K}$, concentration of $\mathrm{CO}$ increased from 7.36 to 37.20 ppm. Meanwhile, concentration of $\mathrm{CO}_{2}$ also increased moderately from 0 to $0.124 \%$ between $293-423 \mathrm{~K}$. In particular, based on these data, the oxidation reaction of benzoic acid was relatively slow in low-temperature phase, especially during stage below $353 \mathrm{~K}$.

Effects of reaction time: It can be seen from Fig. 3 that the reaction time play a critical role on the response intensity with low-temperature oxidation of benzoic acid. After $10 \mathrm{~min}$

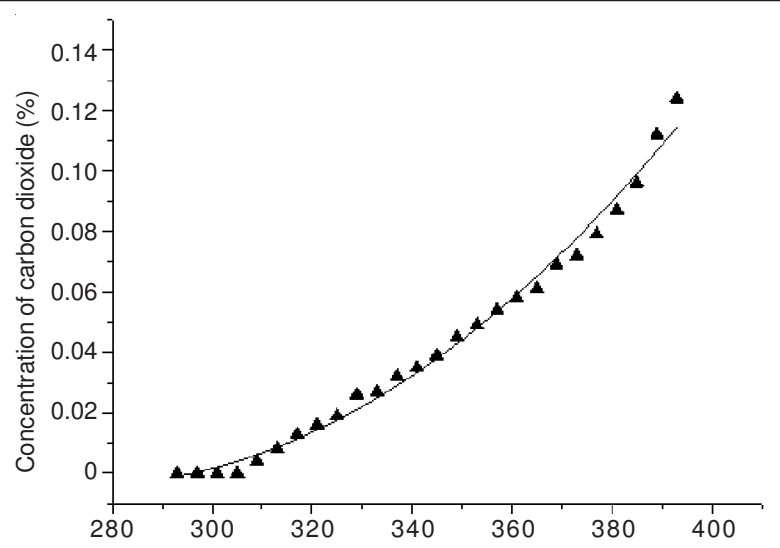

(a) Carbon dioxide

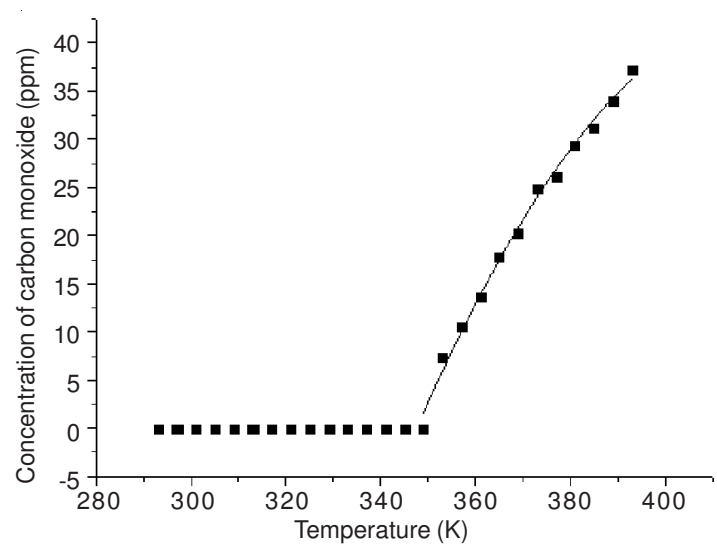

(b) Carbon monoxide

Fig. 2. Gas concentration from the outlet of reaction apparatus

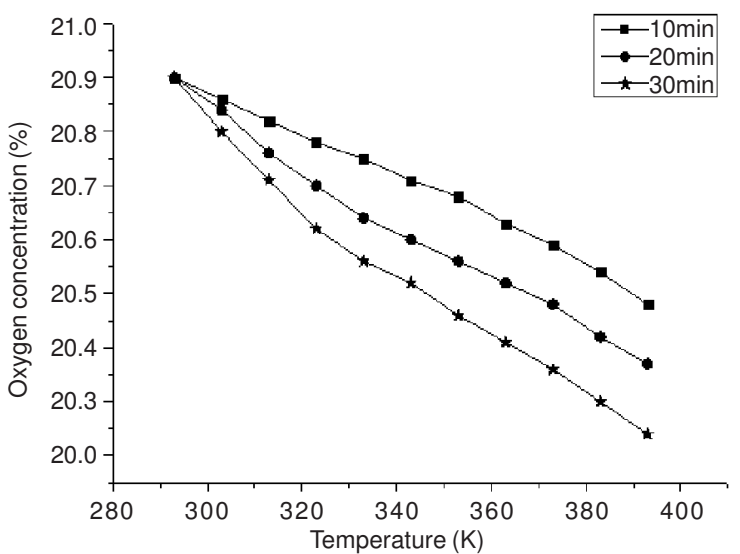

Fig. 3. Oxygen concentration under different reaction times

oxidation, the oxygen concentration was slightly declined from 293 to $423 \mathrm{~K}$. Through $0.5 \mathrm{~h}$ low-temperature oxidation, this data decreased more quickly. At $423 \mathrm{~K}$, the oxygen concentration under reaction time of 10,20 and $30 \mathrm{~min}$ is 20.48 , 20.37 and $20.24 \%$, respectively. The response intensity of benzoic acid grew with the increasing reaction time.

Reaction pathway: The oxidation products of benzoic acid were qualitatively analyzed via coupling of GC-MS. It can be clearly shown in Fig. 4 that acetic acid and 1-hydroxy2-propanone was generated by oxidation of benzoic acid. Through low-temperature oxidation, the carboxyl group attached to the benzene ring was dropped off and formed acetic acid and 1-hydroxy-2-propanone. Then $\mathrm{CO}$ and $\mathrm{CO}_{2}$ 


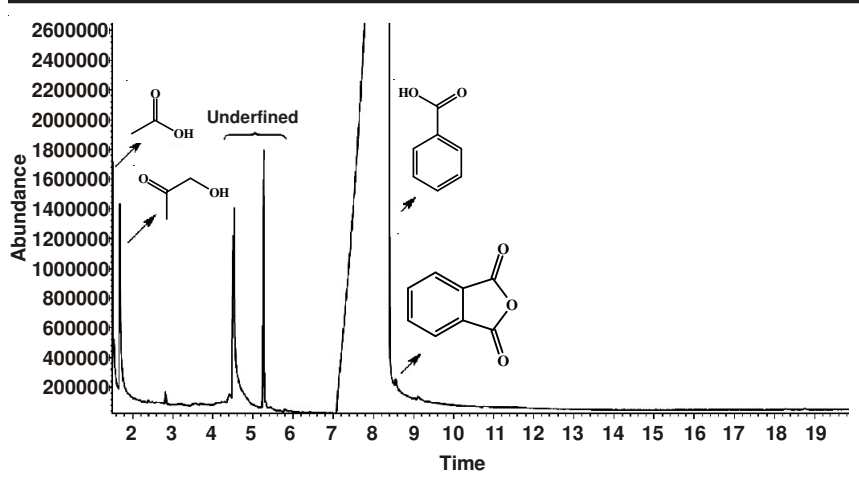

Fig. 4. Chromatograms for composition of oxidation products from benzoic acid, $373 \mathrm{~K}$

were produced by the further oxidation of acetic acid and 1hydroxy-2-propanone. Obviously, the benzene ring did not damage in low-temperature oxidation of benzoic acid and decarboxylation was occurred in the process of oxidation. Combined with oxidation products detected by experiment, it can be inferred that the reaction course of benzoic acid and $\mathrm{O}_{2}$ is as follows (Fig. 5).

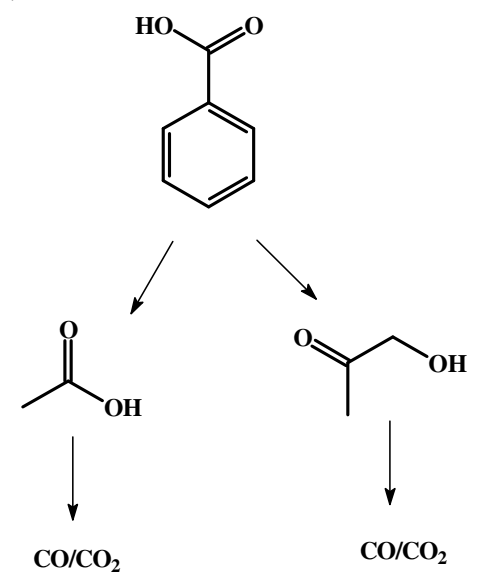

Fig. 5. Simple reaction path

\section{Conclusion}

The oxidation reaction process of benzoic acid is much more complicated polystep reaction ranging from the initial chemisorptions, final polystep decomposition reaction to eventual generation of various products. Based on the analysis result of oxidation course of benzoic acid and its oxidation products in each stage, it can be deduced that carboxyl group present in benzoic acid can make composite oxidation with oxygen under normal temperature. But, its oxidative activity is weaker under normal temperature. And it would constantly improve along with the temperature rise. After the temperature reaches $353 \mathrm{~K}$, its oxidative activity would increase gradually. Furthermore, reaction time exerts the certain impact on activity structure oxidation in benzoic acid. But the impact of reaction temperature is much larger. As long as the temperature rises to a certain value, reaction efficiency would rise greatly. In this paper, the oxidation course of benzoic acid in surface molecular structure of coal was expounded. As the foundation of a series of researches, monocyclic aromatic hydrocarbon was employed as model compound in this paper. Having taken polycyclic aromatic hydrocarbon as the main component of macromolecular structure of coal into account, we would adopt more representative polycyclic aromatic hydrocarbon series as model compound in the further study. In this way, the active group surroundings and bonds in the model compound can be more unanimous with macromolecular structure of solid-state coal, thus revealing coal spontaneous combustion mechanism in a more comprehensive and detailed way.

\section{ACKNOWLEDGEMENTS}

This work is supported by the Project of China National Natural Science Foundation (No. 51074158) and the Fundamental Research Funds for the Central Universities (No. 2012LWBZ10).

\section{REFERENCES}

1. H.H. Wang, B.Z. Dlugogorski and E.M. Kennedy, Combustion Flame, 29, 487 (2003).

2. B.B. Beamis, M.A. Barakat and J.D. St. George, Int. J. Coal Geol., 45, 217 (2001)

3. D.M. Wang, Mine Fire, China University of Mining and Technology Press, Xuzhou, China (2006).

4. V.N. Marinov, Fuel, 56, 153 (1977)

5. J.C. Jones, K.P. Henderson, J. Littlefair and S. Rennie, Fuel, 77, 19 (1998).

6. J.J. Pis, G. de la Puente, E. Fuente, A. Morán and F. Rubiera, Thermochim. Acta, 279, 93 (1996).

7. M. Itay, C.R. Hill and D.A. Glasser, Fuel Process. Technol., 21, 81 (1989).

8. Z.H. Li, J. China Univ. Mining Technol., 25, 111 (1996).

9. D.A. Cole, G.W. Simmons, R.G. Herman, K. Klier and I. Czakó-Nagy, Fuel, 66, 1240 (1987).

10. D. Lopez, Y. Sanada and F. Mondragon, Fuel, 77, 1623 (1998).

11. G.S. Zhang, Y.M. Xie and J.M. Gu, J. China Coal Soc., 28, 473 (2003).

12. M.G. Yu, H.L. Jia , S.J. Yu and R.K. Pan, J. China Coal Soc., 31, 610 (2006).

13. Y.B. Tang, Z.H. Li and Y.L. Yang, Asian J. Chem., 25, 441 (2013).

14. J.S. Gethner, Fuel, 64, 1443 (1985).

15. T. Shi, J. Deng, X.F. Wang and Z.Y. Wen, J. Fuel Chem. Technol., 32, 652 (2004).

16. Y.Y. Zhong, Coal Chemistry, China University of Mining and Technology Press, Xuzhou, China (1989). 